\title{
The endocrine effects of acylated and des-acylated ghrelin
}

This article was published in the following Dove Press journal:

Research and Reports in Endocrine Disorders

24 August 2012

Number of times this article has been viewed

\author{
David E Andrich' \\ Katherine Cianflone ${ }^{2}$ \\ Alain-Steve Comtois' \\ Simon Lalonde' \\ David H St-Pierre' \\ 'Department of Kinesiology, \\ Université du Québec à Montréal \\ (UQAM), Montreal, Canada; ${ }^{2}$ Institut \\ Universitaire de Cardiologie et de \\ Pneumologie de Québec, Quebec, \\ Canada
}

\begin{abstract}
Acylated ghrelin is one of the few peptides known whose isolation and characterization follow the description of its receptor and its basic biological functions. Characterized initially for its somatotrophic properties, ghrelin was shown later to exert various effects on other important physiological functions in mammals, such as appetite, gastric acid secretion, gut motility, insulin sensitivity, adiposity, and energy expenditure. Further, ghrelin influences cardiac function, reproduction, and the immune system as well. Here we present an overview of the discovery and subsequent development of ghrelin as an important peptide hormone involved in the control of energy metabolism in humans and other mammals. Recently reported effects of acylated ghrelin on glucose/lipid uptake, de novo lipogenesis, gluconeogenesis, lipid-droplet formation, fatty acid transport into mitochondria, and mitochondrial activity are particularly emphasized and discussed.
\end{abstract}

Keywords: Acylated ghrelin, des-acylated ghrelin, physiological functions, adipogenesis

\section{Introduction}

The discovery of ghrelin originated from research by Cyril Bowers and collaborators on morphine addiction. ${ }^{1}$ Indeed, the Met-enkephalin peptide analog Tyr-D-Trp-GlyPhe-Met- $\mathrm{NH}_{2}$ that they synthesized in 1976 was termed (D-Trp ${ }^{2}$ )-GHRP because it displayed a weak growth hormone (GH)-releasing activity in vitro. On the other hand, the synthetic peptide was not active in vivo and showed no opiate activity. Through the following years, a large number of peptidic and peptidomimetic GH-releasing peptide (GHRP) analogs, also designated as growth-hormone secretagogues (GHS) were synthesized and tested. In 1989, Bowers' group developed an analog, His-D-Trp-Ala-TrpD-Phe-Lys- $\mathrm{NH}_{2}$ (GHRP-6), that induced the release of GH both in vitro and in vivo, and most importantly was also active in man. Meanwhile, the discovery of GH-releasing factor (GRF) by Guillemin's ${ }^{2}$ and Rivier's ${ }^{3}$ groups in 1982 shadowed for a while the recognition of GHRPs as distinct GHS. However, an intensive research program undertaken by a GHRP believer, Roy Smith and his group at Merck Research Laboratories ${ }^{4}$ led in 1992 to the development of a potent, orally active GHRP peptidomimetic analog, MK-0677, which was biologically specific and distinct from GRF in its GH-releasing activity. Shortly after, in 1996, the same group reported the cloning and characterization of a GTP-binding protein (G protein-coupled receptor or GPCR) in swine and humans that was shown to be the endogenous target for the GH secretagogues. ${ }^{5}$ This GPCR, a typical G protein-coupled seven-transmembrane receptor, was named growth hormone-secretagogue receptor (GHS-R) and shown to be distinct from the receptor that binds GRF. Although it became another orphan GPCR with no identified recognized
Correspondence: David H St-Pierre Department of Kinesiology, Université du Québec à Montréal, 2888 Succursale Centre-Ville, Montreal, Quebec H3C 3P8, Canada Fax + I 5149876616

$\mathrm{Tel}+\mathrm{I} 5$ I4 9873000 ext 5I50

Email st-pierre.david_h@uqam.ca 
ligand, GHS-R was shown to be closely related to the motilin receptor GPR $-38^{6}$ and the neuromedin $\mathrm{U}$ (NMU) receptors NMU-R1 and NMU-R2. ${ }^{7}$ The identification of these related receptors for gastrointestinal (GI) peptides led to the postulate that the ligand for GHS-R was also a peptide from the GI tract. This hypothesis was confirmed with the isolation and characterization of ghrelin by Kojima et al in $1999,{ }^{8}$ using the so-called orphan-receptor strategy. ${ }^{9}$

\section{Background}

Kojima et al isolated ghrelin from rat stomach and determined its amino acid sequence. The name ghrelin comes from the word "ghre," which means "grow" in the Proto-IndoEuropean language. ${ }^{8}$ They found that ghrelin is a 28 -amino acid peptide with a mass of 3371.9 daltons and that it is derived proteolytically from a 117 -amino acid precursor. They also observed that human ghrelin is identical to rat ghrelin, other than two amino acids in positions 11 and 12:

Human GSSFLSPEHQRVQQRKESKKPPAKLQPR

Rat GSSFLSPEHQKAQQRKESKKPPAKLQPR

Uniquely among all other natural peptides isolated so far in animals, Kojima et al showed by electrospray mass spectrometry analysis that ghrelin is esterified on the hydroxyl group of its $\mathrm{Ser}^{3}$ side chain with an octanoylated fatty acid function (acylated ghrelin or AG). They also demonstrated that this modification was required for GH-releasing activity. Later on, they reported that the ghrelin sequence, its $O$-octanoylation, as well as the structure of its receptor GHS$\mathrm{R} 1 \mathrm{a}$, had been highly conserved in vertebrates over millions of years of evolution. ${ }^{10}$ It was also found that threonine could replace serine in position 3 of ghrelin isolated from other species, and that other fatty-acid chains such as decanoic acid could substitute for octanoic acid without significant change in biological activity. ${ }^{11-13}$ Ghrelin is predominantly secreted from X/A-like cells of the oxyntic mucosa in preprandial condition, but its expression was also detected in the gastrointestinal tract, pancreas, the brain, testis, thyroid gland, kidney, and placenta. ${ }^{14}$ The mechanisms underlying the stimulation of AG release remain ill defined; however, GH, somatostatin, and specific nutrients were shown to inhibit its secretion in vitro or in vivo. ${ }^{15-19}$

More recently, in 2008, Yang et $\mathrm{l}^{20}$ identified the enzyme that promotes the formation of an ester bond between octanoic acid and the $\mathrm{Ser}^{3}$ hydroxyl group of ghrelin. This $O$-acyltransferase was termed ghrelin $O$-acyltransferase (GOAT) and is also known as membrane-bound $O$-acyltransferase 4 (MBOAT4). It is a membrane-bound enzyme belonging to a family of hydrophobic membrane-bound acyltransferases of the endoplasmic reticulum that esterify long-chain fatty acids to target proteins. Yang et al demonstrated that GOAT is the only member of this family that octanoylates ghrelin when coexpressed in cultured endocrine cell lines with preproghrelin. ${ }^{20}$ The activity of GOAT requires the presence of catalytic asparagine and histidine residues, which are remarkably conserved in this family. Consistent with its function, GOAT mRNA is mostly found in stomach and intestine, where most ghrelin-secreting tissues are located. It was also reported by Kangawa's group that a nonacylated form of ghrelin, termed des-acylated ghrelin (DAG), is also present in circulation. ${ }^{21}$ Although DAG is believed to be the most abundant circulating form of ghrelin, it is well established that several biological actions of ghrelin, such as GH secretion and feeding behavior, require the presence of the acylated group on ghrelin. On the other hand, a number of studies published during recent years, including ours, ${ }^{22}$ raise the possibility that DAG might also be at the origin of endocrine actions distinct from AG and possibly closely associated to specific pathological states, as further discussed in the following sections. For instance, we reported earlier that both increased AG concentrations and elevated AG/DAG ratios are modulated differentially in insulin-sensitive obese versus insulin-resistant obese postmenopausal women and might be associated with insulin resistance in that population. ${ }^{23}$ More recently, we evaluated the direct effects of AG, DAG, and other peptides of the ghrelin family on preadipocyte proliferation, differentiation, and adipocyte lipid and glucose metabolism in 3T3-L1 cells. ${ }^{24}$ Our results indicate that DAG might be acting through the GHS-R $1^{25}$ pathway in adipocytes and stimulating adipose-tissue hyperplasia and hypertrophy by mechanisms that remain to be elucidated. Altogether, our studies provide evidence that AG and DAG might simultaneously maintain and exacerbate an obese phenotype. It is expected that more endocrine manifestations of DAG will be revealed in the coming years.

\section{Biological activities of ghrelin Ghrelin and $\mathrm{GH}$ secretion}

Although AG is recognized as a potent mediator of somatotroph activity in animal and human models, mice with a deletion of the ghrelin gene display no detectable growth defects. ${ }^{26}$ In addition, no difference in ghrelin levels has been noted between normal and GH-deficient individuals. ${ }^{27-29}$ Interestingly, AG levels were higher in children with poor weight gain than in those with short stature or chronic gastrointestinal dysfunctions, ${ }^{30}$ indicating that $\mathrm{AG}$ would be released in response to an energy deficit rather than being 


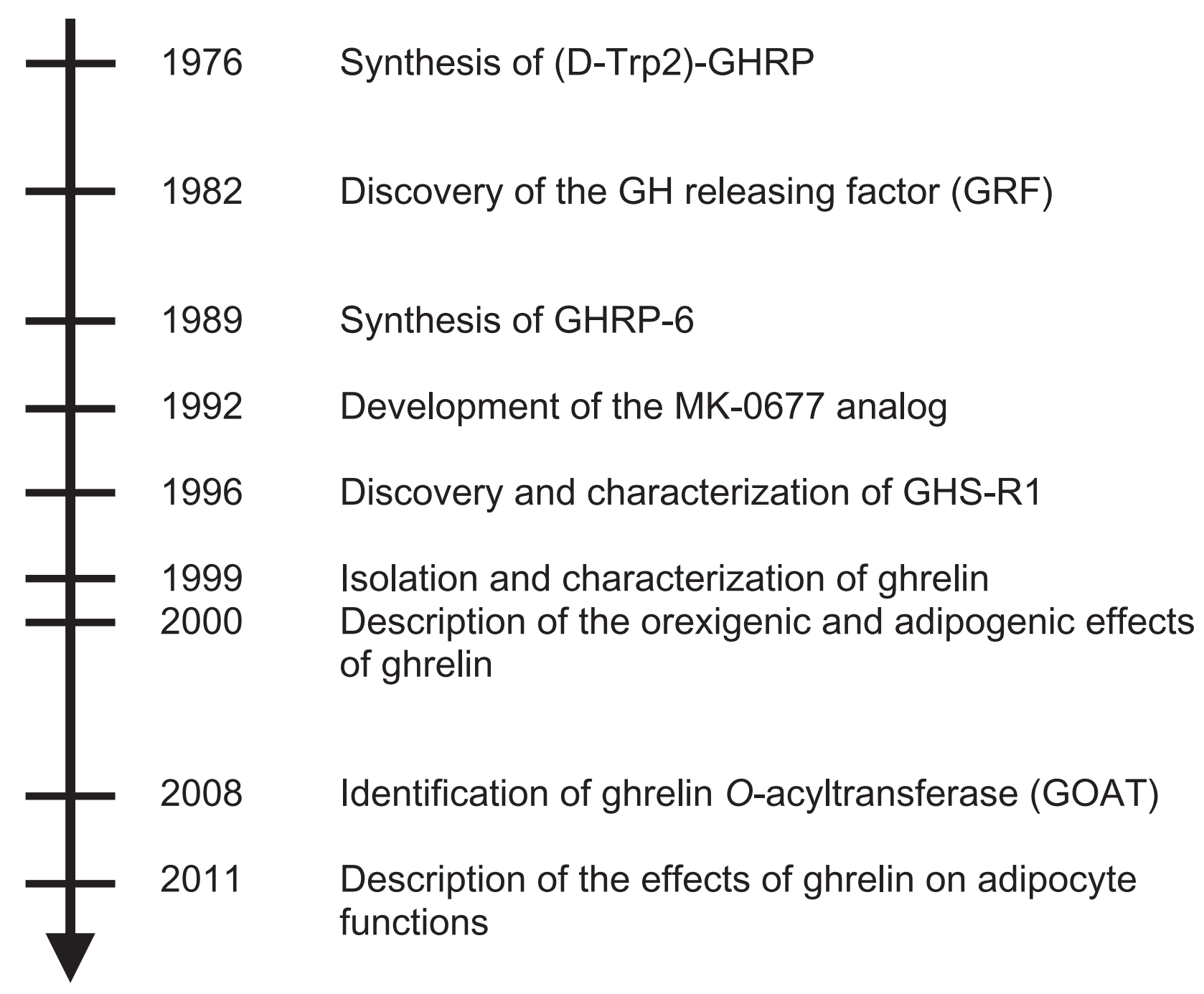

Figure I Milestones for ghrelin, from the synthesis of (D-Trp2)-GHRP in 1976 to the recent description of ghrelin's effects on the regulation of adipocyte functions in 20 II. Abbreviations: GHRP, growth hormone-releasing peptide; GHS-R, growth hormone-secretagogue receptor.

influenced by growth defects per se. Consequently, this either suggests that ghrelin is not essential for the regulation of normal growth functions or that other factors could compensate for its deficient secretion.

\section{Ghrelin and food intake}

It is noteworthy that the first neuroendocrine effects of AG were reported using synthetic analogs of enkephalins before the genuine isolation and characterization of the endogenous peptide were performed. ${ }^{8}$ In fact, synthetic GHS-R1a agonists, such as the GHRPs developed by Bowers, as well as other peptidomimetics such as MK-0677, were all shown to display somatotrophic activity. ${ }^{31}$ Also, intravenous administration of synthetic AG stimulated $\mathrm{ACTH}$, prolactin, and cortisol release in healthy humans, ${ }^{32}$ and a number of other effects of AG on the hypothalamo-pituitary-adrenal axis were described. Tschöp and his colleagues were the first to report that repeated injections of $A G$ stimulated food intake and adiposity in rats. ${ }^{33}$ Regulation of food intake requires sensing energy and modulation of behavior associated with appetite. The hypothalamus, the brain stem, and the limbic system are sensitive to blood levels of metabolic intermediates such as glucose, insulin, and fatty acids that allow the organism to attain nutrient and energy homeostasis. The description of the orexigenic effects of ghrelin emphasize the relevance of considering the peptide as a central and peripheral mediator of energy homeostasis. Further, central administration of AG was shown to stimulate neuronal activation in brain areas known to influence food intake and energy expenditure, such as the arcuate nucleus, the ventromedial nucleus, the dorsomedial nucleus, the paraventricular nucleus, the lateral hypothalamus, the central nucleus of the amygdala, the nucleus of the solitary tract of the brain stem, the ventral tegmental area (VTA), and the nucleus accumbens (NAC) of the 


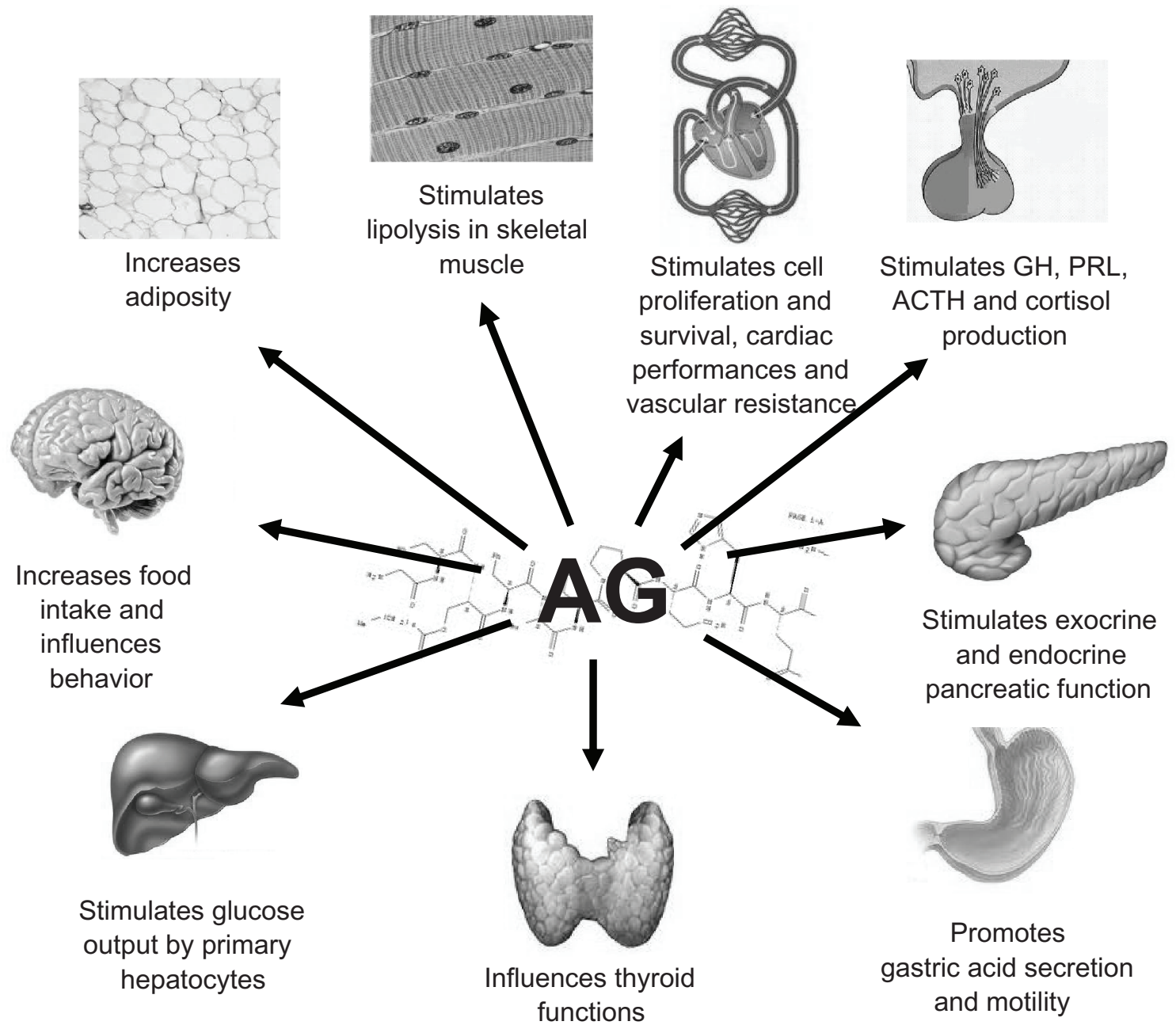

Figure 2 Description of the different metabolic outcomes mediated by acylated ghrelin (AG) in different tissues and organs. Abbreviations: $\mathrm{GH}$, growth hormone; PRL, prolactin; ACTH, adrenocorticotropic hormone.

mesolimbic reward areas. ${ }^{34-43}$ Injected in the hypothalamus, AG increased food intake by stimulating neuropeptide $\mathrm{Y}$ and agouti-related protein while inhibiting pro-opiomelanocortin neurons from the arcuate nucleus. ${ }^{44-46}$ These orexigenic effects of AG could also be mediated through the inhibition of fatty-acid sensing in the hypothalamus. ${ }^{47}$ Interestingly, it seems that AG not only affects appetite by promoting hunger but also through the stimulation of the reward system in dopaminergic and acetylcholine nicotinic neurons from VTA and NAC, ${ }^{48,49}$ associating these effects with hedonism. However, AG could also be involved in the development of addictions such as alcoholism and chemical drug abuse..$^{50-53}$ Other central effects of AG include an increase in learning and memory capacities through the stimulation of serotonin reuptake in the dorsal raphe nucleus ${ }^{54-56}$ and the neuroprotective effect observed through the restriction of dopaminergic neuron loss following the administration of the peptide in the substantia nigra. ${ }^{57-59}$ In both pediatric and adult populations, altered AG concentrations have been observed in pathological conditions associated with excessive or restrained feeding, such as obesity, Prader-Willi syndrome, diabetes mellitus, and anorexia nervosa. ${ }^{60}$ In contrast to the overfeeding reported in children with Prader-Willi syndrome, potential defects in GHS-R1 signaling could explain the observation of elevated AG levels in patients with anorexia nervosa as well as in children with poor weight gain and infants with failure to thrive due to reduced appetite scores. ${ }^{61,62}$ Furthermore, AG is currently considered as a clinical target for stimulating food intake in patients with cachexia. ${ }^{63}$

\section{Ghrelin and energy metabolism Ghrelin and thyroid}

The expression of GHS-R1a has been detected in C cells and follicular cells of the thyroid gland in rats, ${ }^{64,65}$ while GOAT expression was described in the thyroid gland. ${ }^{66}$ In human subjects, it was observed that the administration 
of $A G$ induces an increase in free $T_{4}$ while decreasing thyroid-stimulating hormone (TSH) concentrations, although free $T_{3}$ levels were not affected ${ }^{67}$ In young patients with Graves' disease, total ghrelin levels were positively correlated with TSH, fasting insulin, glucose and homeostasis model assessment, but negatively associated with $\mathrm{T}_{3}$ and $\mathrm{T}_{4}$ levels. ${ }^{68}$ Both DAG and AG levels were found to be significantly lower in hyperthyroid patients, and plasma concentrations were reestablished after return to a euthyroid state. ${ }^{69-72}$ In the same studies, ghrelin levels were correlated with insulin-resistance parameters. Also, the AG-induced stimulation of GH was blunted, while ACTH release was twofold higher in patients with hyperthyroidism versus healthy individuals. These effects were no longer detectable after restoration of normal thyroid function. ${ }^{73,74}$ In contrast, higher total ghrelin levels are observed in patients with hypothyroidism. ${ }^{70}$ In rats, central administration of AG daily for 5 days was shown to increase the weight of the pituitary and to reduce the size of TSH-immunopositive cells in the pituitary. ${ }^{75}$ These effects were associated with a reduction of $\mathrm{TSH}$ and an increase in $\mathrm{T}_{4}$ concentrations in the blood. In $\mathrm{PC}-\mathrm{Cl} 3$ cells, AG stimulates TSH-induced expression of thyroglobulin, thyroperoxidase, and sodium-iodine symporter. ${ }^{64}$ Treatment of rat primary pituitary cells with $\mathrm{T}_{3}$ prevents GHS-R1 mRNA degradation and consequently increases its translation. ${ }^{76}$ Finally, AG treatment stimulates TSH-induced proliferation in FRTL-5 thyroid cells. ${ }^{77}$ These results indicate that dysregulation of ghrelin levels can occur as a consequence of impaired thyroid function. In addition, results derived from cellular models indicate that, in turn, AG influences thyroid functions. As indicated by the divergent information reported in the literature, the influence of $A G$ on the regulation of thyroid functions needs to be further investigated before determining its potential as a clinical target.

\section{Ghrelin and muscle}

In healthy humans, total ghrelin levels are negatively associated with skeletal muscle mass. ${ }^{78}$ We and others had previously observed that AG might have a detrimental role on insulin sensitivity in human, animal, and cellular models..$^{23,79}$ Overall, the influence of AG on skeletal muscle functions remains largely uninvestigated. In elderly individuals, basal and postprandial levels of ghrelin are negatively correlated with fat-free mass and appendicular skeletal muscle mass. ${ }^{80}$ Furthermore, the administration of AG stimulates lipolysis in the skeletal muscle and decreases peripheral insulin sensitivity and energy expenditure..$^{79,81,82}$ Although the results from studies of ghrelin on muscular functions are relatively consistent in humans, they are more ambiguous in rodent models. For instance, in normal young adult rats, the administration of AG twice daily for 4 days stimulates the phosphorylation of Akt and glycogen synthase kinase (GSK) as well as glucose transporter type 4 (GLUT4) mRNA expression in the soleus muscle, but not in the gastrocnemius. ${ }^{83}$ The same treatment also prevents triglyceride accumulation in the muscle of rats submitted to a high-fat diet by reducing protein levels of inflammatory markers NF- $\mathrm{KB}$ and tumor necrosis factor (TNF)- $\alpha$, while increasing the activity of mitochondrial enzymes cytochrome $\mathrm{C}$ oxidase and citrate synthase as well as peroxysome proliferator-activated receptor $\gamma$ (PPAR- $\gamma$ ) expression in the gastrocnemius (mainly glycolytic) muscle. ${ }^{84,85}$ Interestingly, GHS-R1 expression increases in slow-twitch muscle fibers but not in the gastrocnemius muscle of rats submitted to food restriction versus rats fed ad libitum. ${ }^{86}$ Further, treatment of extensor digitorum longus (EDL) muscle with $\mathrm{AG}$ reduces $\mathrm{gCl}$ and gK conductance in rats. ${ }^{87}$ This effect is mediated through the protein kinase $\mathrm{C}$ pathway and abolished by cotreatment with (D-Lys ${ }^{3}$ )-GHRP-6, an antagonist of GHS-R. In addition, lower ghrelin levels are observed in the circulation and in the soleus in trained versus untrained rats. ${ }^{88}$ In nephrectomized rats, $\mathrm{AG}$ increases cytochrome $\mathrm{C}$ oxidase, citrate synthase, PGC-1 $\alpha$, and PGC-1 $\beta$ activity or mRNA levels, and therefore prevents muscle wasting through a mechanism that involves the stimulation of Akt phosphorylation. ${ }^{89}$ Furthermore, in rats submitted to severe burns, the administration of DAG for 24 hours increases EDL muscle mass and reduces TNF- $\alpha$ expression, and in combination with interferon (IFN)- $\gamma$ reduces protein synthesis in the gastrocnemius as well as in C2C12 myotubes. ${ }^{90,91}$ These effects of DAG are mediated through the activation of PI3K and mammalian target of rapamycin pathways. DAG was also shown to restore Akt, GSK-3 $\beta$, 4E-binding protein (BP)1, and forkhead box protein $\mathrm{O} 1$ phosphorylation while reducing muscle atrophy signals such as phospho-NF- $\mathrm{KB}$ levels as well as muscle atrophy F-box and muscle ring finger 1 mRNA expression after treatment with TNF- $\alpha$ and IFN- $\gamma$. Treatment with AG also stimulates myoblast differentiation and myotube formation in vitro. ${ }^{92,93}$ Taken together, the contrasting results that have been reported until now in human and rodent models, as well as in different types of muscle fibers (ie, glycolytic and oxidative), substantiate the need for further studies in which the degradation of AG into DAG, its half-life in the circulation, and its potential indirect neuroendocrine effects are also taken into consideration. 


\section{Ghrelin and adipose tissue}

Soon after the discovery of ghrelin, Tschöp et al were the first to report on its orexigenic and adipogenic properties. ${ }^{33} \mathrm{In}$ obese individuals, total ghrelin levels were shown to be lower in fasting conditions and were less reduced (or not reduced at all) in postprandial as compared to normal subjects. ${ }^{94}$ Interestingly, in women with metabolic disturbances, AG concentrations are higher in individuals with morbid obesity than simple obesity. However, both fasting and postprandial reduction in total ghrelin and AG levels are greater in healthy lean women..$^{95}$ Higher AG and lower DAG concentrations are also observed in obese individuals with or without type 2 diabetes. It is presently debated whether higher or lower GHS-R1 expression is detected in human omental adipose tissues of obese individuals. ${ }^{96,97}$ Meanwhile, the incubation of primary human omental primary adipocytes with either AG or DAG was shown to stimulate PPAR- $\gamma$, SREBP-1, acetylcoenzyme A (CoA) carboxylase (ACC), fatty-acid synthase (FAS), lipoprotein lipase (LPL), and perilipin expression as well as triglyceride accumulation in lipid droplets. ${ }^{96} \mathrm{Also}$, it was reported that treatment of ex vivo human adipose tissue extracts with DAG decreases glycerol release from adipocytes as well as hormone-sensitive lipase expression, while either AG or DAG can increase LPL expression. ${ }^{98}$

For practical reasons, in vivo and in vitro models have so far provided the most important evidence of the influence of ghrelin on adipocyte functions. On the other hand, transgenic animals represent interesting tools to understand the physiological effects of ghrelin. In fact, the inactivation of the GHS-R1 gene reduces adiposity in mice. ${ }^{99}$ This could be mediated through decreased glucose/lipid uptake, de novo lipogenesis, increased insulin sensitivity and thermogenesis in brown adipocytes (expression of uncoupling protein 1 [UCP-1]), and improvement of lipid profiles. Treatment of adipocytes with AG decreases UCP-1 expression, and this effect is reversed by a GHS-R1 antagonist. Like mice, rats with an inactive form of GHS-R1 display increased brown adipose tissue weight, $\mathrm{UCP}-1$ expression, $\mathrm{O}_{2}$ consumption, $\mathrm{CO}_{2}$ production, rectal temperature, and dark-period locomotor activity as well as lower visceral adiposity. ${ }^{100}$ Also, AG administration reduces noradrenaline release in brown adipocytes from wild-type but not from GHS-R1-deficient rats. Both in wild-type and GHdeficient rats, central administration of AG for 8 days increases food intake, body weight, energy efficiency, and percent omental and visceral adiposity. ${ }^{101}$ With regard to the response to chronic central AG administration, there is no difference between wild-type and GH-deficient rats in adipose tissue. In addition, mRNA/protein expression as well as enzymatic activities of $\mathrm{ACC} \alpha$ and phosphorylated ACC $\alpha$, LPL, FAS, stearoyl-CoA desaturase (SCD-1), malonyl-CoA decarboxylase, glucose-6-phosphate dehydrogenase and 6-phosphogluconate dehydrogenase (6PGDH) are increased in response to acute or chronic central administrations of AG in rats. ${ }^{101,102}$ However, an increase in carnitine palmitoyltransferase $1 \mathrm{~m}$ (CPT-1 m), combined with a decrease in malonyl-CoA levels, is observed only in wild-type rats, and the increased protein levels of AMP-activated protein kinase $\alpha 1$ (AMPK $\alpha 1$ ) are detected exclusively in GH-deficient rats. ${ }^{102}$ Central infusion of $A G$ in rats reduces the expression of UCP-1 and UCP-3 in brown adipocytes. ${ }^{102}$ Moreover, in rats submitted to a high-fat diet or overfeeding, decreased ghrelin levels are observed in response to liposuction. ${ }^{103}$ Also, in mouse pups submitted to the same treatment, increased GHS-R1 mRNA expression is observed while AG plasma levels are reduced. ${ }^{104}$ In this last report, white adipose tissue weight as well as protein content or phosphorylation of Akt, PI3K, AMPK, GLUT4 and CPT-1 increased while reduced peroxysome proliferator-activated receptor- $\gamma$ expression was also observed in overfed mouse pups.

The effects of peptides of the ghrelin family (ie, AG, DAG, GHRP-6, and obestatin) were recently investigated in pre- and mature adipocytes. $\mathrm{We}^{97}$ and others ${ }^{105}$ observed that both AG and DAG stimulated adipocyte differentiation. In mature adipocytes, DAG stimulates fatty-acid uptake in 3T3-L1 cells in a more potent manner than AG. These effects are antagonized by a GHS-R1 antagonist and by inhibitors of phospholipase $\mathrm{C}$ and PI3K. Also, DAG significantly decreases lipolysis (ie, glycerol and nonesterified fatty-acid release) in primary adipocytes and 3T3-L1 cells. ${ }^{97,105}$ These results indicate that ghrelin influences preadipocyte proliferation and differentiation, as well as mature adipocyte functions. Although it is difficult to differentiate the specific effects of AG versus DAG in vivo, in vitro models provide a useful alternative. In fact, results indicate that DAG might influence the regulation of adipocyte functions more potently than AG per se. This highlights the relevance of taking into consideration the role of DAG on energy expenditure. It also suggests that further evaluation of the mechanisms responsible for AG des-acylation following its administration in humans and animals is warranted. ${ }^{106}$ This last section suggests the significance of considering DAG as a mediator of pre-, differentiating, and mature adipocyte functions. Results obtained in vitro need to be confirmed in vivo in animal and human models, while future studies could also characterize long-term effects of DAG treatment on subcutaneous and visceral adipocyte physiology. This in turn could provide valuable clinical information regarding the mechanisms underlying the regulation of obesity and its related dysfunctions. 


\section{Ghrelin and liver}

Liver functions are important for the maintenance of glucose, lipid, and cholesterol homeostasis. Furthermore, nonalcoholic fatty liver disease (NAFLD) is closely associated with the development of metabolic dysfunctions such as insulin resistance, type 2 diabetes, and dyslipidemia. ${ }^{107}$ In obese individuals, severe lipid accumulation in the liver is related to lower circulating ghrelin levels. ${ }^{108}$ However, in patients with NAFLD and hepatitis C, DAG and AG plasma levels are shown to be higher than in normal individuals. ${ }^{109,110}$ In addition, in humans, it was suggested that ghrelin levels should be reduced in response to the development of insulin resistance rather than being influenced by liver damage per se. ${ }^{111,112}$

In vivo, peripheral infusion of AG inhibits insulin-induced suppression of hepatic glucose production while stimulating overall glucose uptake in mice. ${ }^{113}$ These results were confirmed with observation of an AG stimulatory effect on hepatic glucose release and its inhibition in response to a cotreatment with DAG in porcine primary hepatocytes in vitro. ${ }^{114}$ In another study, peripheral administration of AG induced a lipogenic and glucogenic response in the liver, and this was mediated through reductions in AMPK activity as well as Akt and GSK phosphorylation. ${ }^{83,84}$ Furthermore, hepatic mitochondrial activity was decreased by $44 \%$ following the administration of AG; however, this effect was not observed after treating primary hepatocytes with AG. ${ }^{115}$ This suggests the influence of the des-acylated form of ghrelin DAG. In response to the central administration of AG, protein/ mRNA expression or enzymatic activity was increased for SCD-1, ACC $\alpha$, pACC $\alpha$, AMPK $\alpha 1$, AMPK $\alpha 2$, FAS, G6PDH, and 6PGDH, while the opposite effect was observed for CTP-1 and malonyl-CoA in wild-type rats. ${ }^{101}$ Interestingly, all these effects are also shown to occur in wild-type and GH-deficient rats. However, the authors suggest that this decrease in CPT-1 expression and in malonyl-CoA concentrations could be GH-specific, since it could not be detected in GH-deficient rats. Studies on liver functions report that AG or DAG could increase de novo lipogenesis and fattyacid desaturation while inhibiting mitochondrial transport. Although it remains speculative, this suggests a potential role of ghrelin in the regulation of lipid infiltration in the liver and could consequently lead to clinical applications.

\section{Conclusion}

Other than stimulating GH release, ghrelin has also been shown to influence appetite, energy expenditure, adipocytes, myocytes, and hepatocytes as well as the reproductive and immune systems. ${ }^{16,117}$ Nonetheless, important questions remain regarding the tissue-specific activity of $A G$ and its des-acylated counterpart DAG. For instance, convincing evidence indicates that although devoid of orexigenic activity, DAG rather than AG could modulate adipocyte functions such as preadipocyte proliferation, differentiation, energetic substrate uptake, lipogenesis, triglyceride synthesis, fatty-acid transport into mitochondria, and mitochondrial activity. The existence of such an array of ghrelin-supported phenomena highlights, for instance, the importance of evaluating the contribution of AG degradation to DAG following its administration in clinical and animal models. Also, the potential interaction between DAG and a receptor displaying a high degree of homology with GHS-R1, such as GPR38, deserves to be investigated. ${ }^{118}$ Overall, although ghrelin was discovered less than 15 years ago, it has shed light on several key mechanisms that support its role in endocrine and neuroendocrine regulation of major metabolic functions.

\section{Disclosure}

The authors report no conflicts of interest in this work.

\section{References}

1. Bowers CY, Chamg J, Momany F, Folkers K. Effect of the Enkephalins and Enkephalin Analogs on the Release of Pituitary Hormones in Vitro. Amsterdam: Elsevier/North Holland Biomedical Press; 1977.

2. Guillemin R, Brazeau P, Bohlen P, Esch F, Ling N, Wehrenberg WB. Growth hormone-releasing factor from a human pancreatic tumor that caused acromegaly. Science. 1982;218(4572):585-587.

3. Rivier J, Spiess J, Thorner M, Vale W. Characterization of a growth hormone-releasing factor from a human pancreatic islet tumour. Nature. 1982;300(5889):276-278.

4. Patchett AA, Nargund RP, Tata JR, et al. Design and biological activities of L-163,191 (MK-0677): a potent, orally active growth hormone secretagogue. Proc Natl Acad Sci U S A. 1995;92(15):7001-7005.

5. Howard AD, Feighner SD, Cully DF, et al. A receptor in pituitary and hypothalamus that functions in growth hormone release. Science. 1996;273(5277):974-977.

6. Feighner SD, Tan CP, McKee KK, et al. Receptor for motilin identified in the human gastrointestinal system. Science. 1999;284(5423):2184-2188.

7. Howard AD, Wang R, Pong SS, et al. Identification of receptors for neuromedin U and its role in feeding. Nature. 2000;406(6791):70-74.

8. Kojima M, Hosoda H, Date Y, Nakazato M, Matsuo H, Kangawa K. Ghrelin is a growth-hormone-releasing acylated peptide from stomach. Nature. 1999;402(6762):656-660.

9. Civelli O, Nothacker HP, Saito Y, Wang Z, Lin SH, Reinscheid RK Novel neurotransmitters as natural ligands of orphan G-protein-coupled receptors. Trends Neurosci. 2001;24(4):230-237.

10. Kojima M, Kangawa K. Ghrelin: structure and function. Physiol Rev. 2005;85(2):495-522.

11. Matsumoto M, Hosoda H, Kitajima Y, et al. Structure-activity relationship of ghrelin: pharmacological study of ghrelin peptides. Biochem Biophys Res Commun. 2001;287(1):142-146.

12. Nishi Y, Yoh J, Hiejima H, Kojima M. Structures and molecular forms of the ghrelin-family peptides. Peptides. 2011;32(11):2175-2182.

13. Yoh J, Nishi Y, Hosoda H, et al. Plasma levels of n-decanoyl ghrelin, another acyl- and active-form of ghrelin, in human subjects and the effect of glucose- or meal-ingestion on its dynamics. Regul Pept. 2011;167(1):140-148 
14. Kirchner H, Heppner KM, Tschop MH. The role of ghrelin in the control of energy balance. Handb Exp Pharmacol. 2012;209:161-184.

15. Seoane LM, Al-Massadi O, Barreiro F, Dieguez C, Casanueva FF. Growth hormone and somatostatin directly inhibit gastric ghrelin secretion. An in vitro organ culture system. $J$ Endocrinol Invest. 2007;30(9):RC22-RC25.

16. Foster-Schubert KE, Overduin J, Prudom CE, et al. Acyl and total ghrelin are suppressed strongly by ingested proteins, weakly by lipids, and biphasically by carbohydrates. J Clin Endocrinol Metab. 2008;93(5): 1971-1979.

17. Marzullo P, Caumo A, Savia G, et al. Predictors of postabsorptive ghrelin secretion after intake of different macronutrients. J Clin Endocrinol Metab. 2006;91(10):4124-4130.

18. Gomez G, Englander EW, Greeley GH Jr. Nutrient inhibition of ghrelin secretion in the fasted rat. Regul Pept. 2004;117(1):33-36.

19. Erdmann J, Lippl F, Schusdziarra V. Differential effect of protein and fat on plasma ghrelin levels in man. Regul Pept. 2003;116(1-3): 101-107.

20. Yang J, Brown MS, Liang G, Grishin NV, Goldstein JL. Identification of the acyltransferase that octanoylates ghrelin, an appetite-stimulating peptide hormone. Cell. 2008;132(3):387-396.

21. Hosoda H, Kojima M, Matsuo H, Kangawa K. Ghrelin and des-acyl ghrelin: two major forms of rat ghrelin peptide in gastrointestinal tissue. Biochem Biophys Res Commun. 2000;279(3):909-913.

22. Benso A, St-Pierre DH, Prodam F, et al. Metabolic effects of overnight continuous infusion of unacylated ghrelin in humans. Eur J Endocrinol. 2012;166(5):911-916

23. St-Pierre DH, Karelis AD, Coderre L, et al. Association of acylated and nonacylated ghrelin with insulin sensitivity in overweight and obese postmenopausal women. J Clin Endocrinol Metab. 2007;92(1): 264-269.

24. Miegueu P, Pierre DS, Broglio F, Cianflone K. Effect of desacyl ghrelin, obestatin and related peptides on triglyceride storage, metabolism and GHSR signaling in 3T3-L1 adipocytes. J Cell Biochem. 2011;112(2): 704-714.

25. Gnanapavan S, Kola B, Bustin SA, et al. The tissue distribution of the mRNA of ghrelin and subtypes of its receptor, GHS-R, in humans. $J$ Clin Endocrinol Metab. 2002;87(6):2988.

26. Kang K, Zmuda E, Sleeman MW. Physiological role of ghrelin as revealed by the ghrelin and GOAT knockout mice. Peptides. 2011; 32(11):2236-2241.

27. Tarantini B, Ciuoli C, Checchi S, et al. Serum ghrelin levels in growth hormone-sufficient and growth hormone-deficient patients during growth hormone-releasing hormone plus arginine test. J Endocrinol Invest. 2009;32(4):335-337.

28. Lopez-Siguero JP, Lopez-Canti LF, Espino R, et al. Effect of recombinant growth hormone on leptin, adiponectin, resistin, interleukin-6, tumor necrosis factor-alpha and ghrelin levels in growth hormonedeficient children. $J$ Endocrinol Invest. 2011;34(4):300-306.

29. Jung CH, Lee WY, Rhee EJ, et al. Serum ghrelin and leptin levels in adult growth hormone deficiency syndrome. Arch Med Res. 2006;37(5): 612-618.

30. Pinsker JE, Ondrasik D, Chan D, et al. Total and acylated ghrelin levels in children with poor growth. Pediatr Res. 2011;69(6):517-521.

31. Anderson LL, Jeftinija S, Scanes CG, et al. Physiology of ghrelin and related peptides. Domest Anim Endocrinol. 2005;29(1):111-144.

32. Takaya K, Ariyasu H, Kanamoto N, et al. Ghrelin strongly stimulates growth hormone release in humans. J Clin Endocrinol Metab. 2000; 85(12):4908-4911.

33. Tschöp M, Smiley DL, Heiman ML. Ghrelin induces adiposity in rodents. Nature. 2000;407(6806):908-913.

34. Olszewski PK, Grace MK, Billington CJ, Levine AS. Hypothalamic paraventricular injections of ghrelin: effect on feeding and c-Fos immunoreactivity. Peptides. 2003;24(6):919-923.

35. Olszewski PK, Li D, Grace MK, Billington CJ, Kotz CM, Levine AS. Neural basis of orexigenic effects of ghrelin acting within lateral hypothalamus. Peptides. 2003;24(4):597-602.
36. Wren AM, Small CJ, Abbott CR, et al. Ghrelin causes hyperphagia and obesity in rats. Diabetes. 2001;50(11):2540-2547.

37. Wren AM, Small CJ, Ward HL, et al. The novel hypothalamic peptide ghrelin stimulates food intake and growth hormone secretion. Endocrinology. 2000;141(11):4325-4328.

38. Faulconbridge LF, Cummings DE, Kaplan JM, Grill HJ. Hyperphagic effects of brainstem ghrelin administration. Diabetes. 2003;52(9): 2260-2265.

39. Egecioglu E, Jerlhag E, Salome N, et al. Ghrelin increases intake of rewarding food in rodents. Addict Biol. 2010;15(3):304-311.

40. Perello M, Sakata I, Birnbaum S, et al. Ghrelin increases the rewarding value of high-fat diet in an orexin-dependent manner. Biol Psychiatry. 2010;67(9):880-886.

41. Egecioglu E, Skibicka KP, Hansson C, et al. Hedonic and incentive signals for body weight control. Rev Endocr Metab Disord. 2011;12(3): 141-151.

42. Skibicka KP, Hansson C, Egecioglu E, Dickson SL. Role of ghrelin in food reward: impact of ghrelin on sucrose self-administration and mesolimbic dopamine and acetylcholine receptor gene expression. Addict Biol. 2012;17(1):95-107.

43. Malik S, McGlone F, Bedrossian D, Dagher A. Ghrelin modulates brain activity in areas that control appetitive behavior. Cell Metab. 2008;7(5): 400-409.

44. Wang L, Saint-Pierre DH, Tache Y. Peripheral ghrelin selectively increases Fos expression in neuropeptide $\mathrm{Y}$ - synthesizing neurons in mouse hypothalamic arcuate nucleus. Neurosci Lett. 2002;325(1): $47-51$.

45. Kamegai J, Tamura H, Shimizu T, Ishii S, Sugihara H, Wakabayashi I. Central effect of ghrelin, an endogenous growth hormone secretagogue, on hypothalamic peptide gene expression. Endocrinology. 2000; 141(12):4797-4800.

46. Riediger T, Traebert M, Schmid HA, Scheel C, Lutz TA, Scharrer E. Site-specific effects of ghrelin on the neuronal activity in the hypothalamic arcuate nucleus. Neurosci Lett. 2003;341(2):151-155.

47. Jones RB, McKie S, Astbury N, et al. Functional neuroimaging demonstrates that ghrelin inhibits the central nervous system response to ingested lipid. Gut. Epub February 7, 2012.

48. Jerlhag E, Egecioglu E, Dickson SL, Douhan A, Svensson L, Engel JA. Ghrelin administration into tegmental areas stimulates locomotor activity and increases extracellular concentration of dopamine in the nucleus accumbens. Addict Biol. 2007;12(1):6-16.

49. Jerlhag E, Egecioglu E, Dickson SL, Andersson M, Svensson L, Engel JA. Ghrelin stimulates locomotor activity and accumbal dopamine-overflow via central cholinergic systems in mice: implications for its involvement in brain reward. Addict Biol. 2006;11(1):45-54.

50. Soderpalm B, Ericson M. Neurocircuitry involved in the development of alcohol addiction: the dopamine system and its access points. Curr Top Behav Neurosci. Epub November 18, 2011.

51. Kaur S, Ryabinin AE. Ghrelin receptor antagonism decreases alcohol consumption and activation of perioculomotor urocortin-containing neurons. Alcohol Clin Exp Res. 2010;34(9):1525-1534.

52. Kraus T, Schanze A, Groschl M, et al. Ghrelin levels are increased in alcoholism. Alcohol Clin Exp Res. 2005;29(12):2154-2157.

53. Jerlhag E, Egecioglu E, Dickson SL, Engel JA. Ghrelin receptor antagonism attenuates cocaine- and amphetamine-induced locomotor stimulation, accumbal dopamine release, and conditioned place preference. Psychopharmacology. 2010;211(4):415-422.

54. Carlini VP, Gaydou RC, Schioth HB, de Barioglio SR. Selective serotonin reuptake inhibitor (fluoxetine) decreases the effects of ghrelin on memory retention and food intake. Regul Pept. 2007;140(1-2): $65-73$.

55. Carlini VP, Ghersi M, Schioth HB, de Barioglio SR. Ghrelin and memory: differential effects on acquisition and retrieval. Peptides. 2010;31(6):1190-1193.

56. Carlini VP, Monzon ME, Varas MM, et al. Ghrelin increases anxietylike behavior and memory retention in rats. Biochem Biophys Res Commun. 2002;299(5):739-743. 
57. Andrews ZB, Erion D, Beiler R, et al. Ghrelin promotes and protects nigrostriatal dopamine function via a UCP2-dependent mitochondrial mechanism. J Neurosci. 2009;29(45):14057-14065.

58. Jiang H, Li LJ, Wang J, Xie JX. Ghrelin antagonizes MPTP-induced neurotoxicity to the dopaminergic neurons in mouse substantia nigra. Exp Neurol. 2008;212(2):532-537.

59. Moon M, Kim HG, Hwang L, et al. Neuroprotective effect of ghrelin in the 1-methyl-4-phenyl-1,2,3,6-tetrahydropyridine mouse model of Parkinson's disease by blocking microglial activation. Neurotox Res. 2009;15(4):332-347.

60. Lim CT, Korbonits M. Paediatric endocrine aspects of ghrelin. Pediatr Endocrinol Rev. 2012;9(3):628-638.

61. Muller TD, Tschop MH, Jarick I, et al. Genetic variation of the ghrelin activator gene ghrelin O-acyltransferase (GOAT) is associated with anorexia nervosa. J Psychiatr Res. 2011;45(5):706-711.

62. Tannenbaum GS, Ramsay M, Martel C, et al. Elevated circulating acylated and total ghrelin concentrations along with reduced appetite scores in infants with failure to thrive. Pediatr Res. 2009;65(5): 569-573.

63. Strasser F. Clinical application of ghrelin. Curr Pharm Des. Epub May 23, 2012.

64. Morillo-Bernal J, Fernandez-Santos JM, De Miguel M, et al. Ghrelin potentiates TSH-induced expression of the thyroid tissue-specific genes thyroglobulin, thyroperoxidase and sodium-iodine symporter, in rat PC-Cl3 Cells. Peptides. 2011;32(11):2333-2339.

65. Lim CT, Kola B, Grossman A, Korbonits M. The expression of ghrelin O-acyltransferase (GOAT) in human tissues. Endocr J. 2011;58(8): 707-710.

66. Ueberberg B, Unger N, Saeger W, Mann K, Petersenn S. Expression of ghrelin and its receptor in human tissues. Horm Metab Res. 2009;41(11): 814-821.

67. Kluge M, Riedl S, Uhr M, et al. Ghrelin affects the hypothalamuspituitary-thyroid axis in humans by increasing free thyroxine and decreasing TSH in plasma. Eur J Endocrinol. 2010;162(6):1059-1065.

68. Sawicka B, Bossowski A, Szalecki M, et al. Relationship between metabolic parameters and thyroid hormones and the level of gastric peptides in children with autoimmune thyroid diseases. J Pediatr Endocrinol Metab. 2010;23(4):345-354

69. El Gawad SS, El-Kenawy FM, Mousa AA, Omar AA. Plasma levels of resistin and ghrelin before and after treatment in patients with hyperthyroidism. Endocr Pract. 2012;18(3):376-381.

70. Kosowicz J, Baumann-Antczak A, Ruchala M, Gryczynska M, Gurgul E, Sowinski J. Thyroid hormones affect plasma ghrelin and obestatin levels. Horm Metab Res. 2011;43(2):121-125.

71. Tanda ML, Lombardi V, Genovesi M, et al. Plasma total and acylated Ghrelin concentrations in patients with clinical and subclinical thyroid dysfunction. J Endocrinol Invest. 2009;32(1):74-78.

72. Altinova AE, Toruner FB, Akturk M, et al. Reduced serum acylated ghrelin levels in patients with hyperthyroidism. Horm Res. 2006;65(6): 295-299.

73. Molica P, Nascif SO, Correa-Silva SR, de Sa LB, Vieira JG, Lengyel AM. Effects of ghrelin, GH-releasing peptide-6 (GHRP-6) and GHRH on GH, ACTH and cortisol release in hyperthyroidism before and after treatment. Pituitary. 2010;13(4):315-323.

74. Riis AL, Hansen TK, Moller N, Weeke J, Jorgensen JO. Hyperthyroidism is associated with suppressed circulating ghrelin levels. J Clin Endocrinol Metab. 2003;88(2):853-857.

75. Sosic-Jurjevic B, Stevanovic D, Milosevic V, Sekulic M, Starcevic V. Central ghrelin affects pituitary-thyroid axis: histomorphological and hormonal study in rats. Neuroendocrinology. 2009;89(3): 327-336

76. Kamegai J, Tamura H, Ishii S, Sugihara H, Wakabayashi I. Thyroid hormones regulate pituitary growth hormone secretagogue receptor gene expression. J Neuroendocrino. 2001;13(3):275-278.

77. Park YJ, Lee YJ, Kim SH, et al. Ghrelin enhances the proliferating effect of thyroid stimulating hormone in FRTL-5 thyroid cells. Mol Cell Endocrinol. 2008;285(1-2):19-25.
78. Tai K, Visvanathan R, Hammond AJ, Wishart JM, Horowitz M, Chapman IM. Fasting ghrelin is related to skeletal muscle mass in healthy adults. Eur J Nutr. 2009;48(3):176-183.

79. Vestergaard ET, Gormsen LC, Jessen N, et al. Ghrelin infusion in humans induces acute insulin resistance and lipolysis independent of growth hormone signaling. Diabetes. 2008;57(12):3205-3210.

80. Bertoli S, Magni P, Krogh V, et al. Is ghrelin a signal of decreased fat-free mass in elderly subjects? Eur J Endocrinol. 2006;155(2):321-330.

81. Vestergaard ET, Djurhuus CB, Gjedsted J, et al. Acute effects of ghrelin administration on glucose and lipid metabolism. J Clin Endocrinol Metab. 2008;93(2):438-444.

82. Vestergaard ET, Buhl M, Gjedsted J, et al. Acute peripheral metabolic effects of intraarterial ghrelin infusion in healthy young men. J Clin Endocrinol Metab. 2011;96(2):468-477.

83. Barazzoni R, Zanetti M, Cattin MR, et al. Ghrelin enhances in vivo skeletal muscle but not liver AKT signaling in rats. Obesity. 2007;15(11): 2614-2623.

84. Barazzoni R, Bosutti A, Stebel M, et al. Ghrelin regulates mitochondriallipid metabolism gene expression and tissue fat distribution in liver and skeletal muscle. Am J Physiol Endocrinol Metab. 2005;288(1): E228-E235.

85. Barazzoni R, Zanetti M, Semolic A, et al. High-fat diet with acyl-ghrelin treatment leads to weight gain with low inflammation, high oxidative capacity and normal triglycerides in rat muscle. PloS One. 2011;6(10): e26224.

86. Pardo M, Roca-Rivada A, Al-Massadi O, Seoane LM, Camina JP, Casanueva FF. Peripheral leptin and ghrelin receptors are regulated in a tissue-specific manner in activity-based anorexia. Peptides. 2010;31(10):1912-1919.

87. Pierno S, De Luca A, Desaphy JF, et al. Growth hormone secretagogues modulate the electrical and contractile properties of rat skeletal muscle through a ghrelin-specific receptor. Br J Pharmacol. 2003;139(3):575-584.

88. Ghanbari-Niaki A, Abednazari H, Tayebi SM, Hossaini-Kakhak A, Kraemer RR. Treadmill training enhances rat agouti-related protein in plasma and reduces ghrelin levels in plasma and soleus muscle. Metab Clin Exp. 2009;58(12):1747-1752.

89. Barazzoni R, Zhu X, Deboer M, et al. Combined effects of ghrelin and higher food intake enhance skeletal muscle mitochondrial oxidative capacity and AKT phosphorylation in rats with chronic kidney disease. Kidney Int. 2010;77(1):23-28.

90. Balasubramaniam A, Joshi R, Su C, et al. Ghrelin inhibits skeletal muscle protein breakdown in rats with thermal injury through normalizing elevated expression of E3 ubiquitin ligases MuRF1 and MAFbx. Am J Physiol Regul Integr Comp Physiol. 2009;296(4):R893-R901.

91. Sheriff S, Kadeer N, Joshi R, Friend LA, James JH, BalasubramaniamA. Des-acyl ghrelin exhibits pro-anabolic and anti-catabolic effects on C2C12 myotubes exposed to cytokines and reduces burn-induced muscle proteolysis in rats. Mol Cell Endocrinol. 2012;351(2): 286-295.

92. Montoya-Flores D, Mora O, Tamariz E, et al. Ghrelin stimulates myogenic differentiation in a mouse muscle satellite cell line and in primary cultures of bovine myoblasts. J Anim Physiol Anim Nutr (Berl). Epub July $21,2011$.

93. Filigheddu N, Gnocchi VF, Coscia M, et al. Ghrelin and des-acyl ghrelin promote differentiation and fusion of $\mathrm{C} 2 \mathrm{C} 12$ skeletal muscle cells. Mol Biol Cell. 2007;18(3):986-994.

94. Shiiya T, Nakazato M, Mizuta M, et al. Plasma ghrelin levels in lean and obese humans and the effect of glucose on ghrelin secretion. J Clin Endocrinol Metab. 2002;87(1):240-244.

95. Zwirska-Korczala K, Konturek SJ, Sodowski M, et al. Basal and postprandial plasma levels of PYY, ghrelin, cholecystokinin, gastrin and insulin in women with moderate and morbid obesity and metabolic syndrome. J Physiol Pharmacol. 2007;58 Suppl 1:13-35.

96. Rodriguez A, Gomez-Ambrosi J, Catalan V, et al. Acylated and desacyl ghrelin stimulate lipid accumulation in human visceral adipocytes. Int J Obes (Lond). 2009;33(5):541-552. 
97. Miegueu P, St Pierre D, Broglio F, Cianflone K. Effect of desacyl ghrelin, obestatin and related peptides on triglyceride storage, metabolism and GHSR signaling in 3T3-L1 adipocytes. $J$ Cell Biochem. 2011;112(2):704-714.

98. Kos K, Harte AL, O'Hare PJ, Kumar S, McTernan PG. Ghrelin and the differential regulation of des-acyl (DSG) and octanoyl ghrelin (OTG) in human adipose tissue (AT). Clin Endocrinol. 2009;70(3):383-389.

99. Lin L, Saha PK, Ma X, et al. Ablation of ghrelin receptor reduces adiposity and improves insulin sensitivity during aging by regulating fat metabolism in white and brown adipose tissues. Aging Cell. 2011;10(6):996-1010.

100. Mano-Otagiri A, Iwasaki-Sekino A, Nemoto T, et al. Genetic suppression of ghrelin receptors activates brown adipocyte function and decreases fat storage in rats. Regul Pept. 2010;160(1-3):81-90.

101. Sangiao-Alvarellos S, Vazquez MJ, Varela L, et al. Central ghrelin regulates peripheral lipid metabolism in a growth hormone-independent fashion. Endocrinology. 2009;150(10):4562-4574.

102. Theander-Carrillo C, Wiedmer P, Cettour-Rose P, et al. Ghrelin action in the brain controls adipocyte metabolism. J Clin Invest. 2006;116(7): 1983-1993.

103. Schreiber JE, Singh NK, Shermak MA. The effect of liposuction and diet on ghrelin, adiponectin, and leptin levels in obese Zucker rats. Plast Reconstr Surg. 2006;117(6):1829-1835.

104. Soares VM, Garcia-Souza EP, Lacerda-Miranda G, Moura AS. Early life overfeeding decreases acylated ghrelin circulating levels and upregulates GHSR1a signaling pathway in white adipose tissue of obese young mice. Regul Pept. 2012;174(1-3):6-11.

105. Choi K, Roh SG, Hong YH, et al. The role of ghrelin and growth hormone secretagogues receptor on rat adipogenesis. Endocrinology. 2003;144(3):754-759.

106. Satou M, Nakamura Y, Ando H, Sugimoto H. Understanding the functional significance of ghrelin processing and degradation. Peptides. 2011;32(11):2183-2190.

107. Pettinelli P, Obregon AM, Videla LA. Molecular mechanisms of steatosis in nonalcoholic fatty liver disease. Nutr Hosp. 2011;26(3):441-450.
108. Pisto P, Ukkola O, Santaniemi M, Kesaniemi YA. Plasma adiponectin - an independent indicator of liver fat accumulation. Metab Clin Exp. 2011;60(11):1515-1520.

109. Estep M, Abawi M, Jarrar M, et al. Association of obestatin, ghrelin, and inflammatory cytokines in obese patients with non-alcoholic fatty liver disease. Obe Surg. 2011;21(11):1750-1757.

110. Pavlidis C, Panoutsopoulos GI, Tiniakos D, Koutsounas S, Vlachogiannakos J, Zouboulis-Vafiadis I. Serum leptin and ghrelin in chronic hepatitis C patients with steatosis. World J Gastroenterol. 2011;17(46):5097-5104.

111. Sajjad A, Mottershead M, Syn WK, Jones R, Smith S, Nwokolo CU. Ciprofloxacin suppresses bacterial overgrowth, increases fasting insulin but does not correct low acylated ghrelin concentration in non-alcoholic steatohepatitis. Aliment Pharmacol Ther. 2005;22(4): 291-299.

112. Marchesini G, Pagotto U, Bugianesi E, et al. Low ghrelin concentrations in nonalcoholic fatty liver disease are related to insulin resistance. $J$ Clin Endocrinol Metab. 2003;88(12):5674-5679.

113. Heijboer AC, van den Hoek AM, Parlevliet ET, et al. Ghrelin differentially affects hepatic and peripheral insulin sensitivity in mice. Diabetologia. 2006;49(4):732-738.

114. Gauna C, Delhanty PJ, Hofland LJ, et al. Ghrelin stimulates, whereas des-octanoyl ghrelin inhibits, glucose output by primary hepatocytes. J Clin Endocrinol Metab. 2005;90(2):1055-1060.

115. Rigault C, Le Borgne F, Georges B, Demarquoy J. Ghrelin reduces hepatic mitochondrial fatty acid beta oxidation. J Endocrinol Invest. 2007;30(4):RC4-RC8.

116. Muccioli G, Lorenzi T, Lorenzi M, et al. Beyond the metabolic role of ghrelin: a new player in the regulation of reproductive function. Peptides. 2011;32(12):2514-2521.

117. Baatar D, Patel K, Taub DD. The effects of ghrelin on inflammation and the immune system. Mol Cell Endocrinol. 2011;340(1):44-58.

118. Miegueu P, Cianflone K, Richard D, St-Pierre DH. Motilin stimulates preadipocyte proliferation and differentiation and adipocyte lipid storage. Am J Physiol Endocrinol Metab. 2011;301(5):E758-E766.
Research and Reports in Endocrine Disorders

\section{Publish your work in this journal}

Research and Reports in Endocrine Disorders is an international, peerreviewed, open access journal publishing original research, reports, reviews and commentaries on all areas of endocrinology, endocrine disorders and therapeutic interventions. The manuscript management system is completely online and includes a very quick and fair

\section{Dovepress}

peer-review system. Visit http://www.dovepress.com/testimonials.php to read real quotes from published authors. 